\title{
AÇÕES DE INTERAÇÃO UNIVERSIDADE-EMPRESA COMO FORMA DE MINIMIZAR A EVASÃO DAS MULHERES NOS CURSOS DE STEM
}

DOI: 10.37702/2175-957X.COBENGE.2021.3521

Kátia Simone Teixeira da Silva de La Salles - katia.salles@ufma.br Universidade Federal do Maranhão AV. sao Luis rei de franca 48 65065-470 - sao luis - MA

Wendell Ferreira de La Salles - wendellsalles@hotmail.com Universidade Federal do Maranhão Avenida São Luís Rei de França 48 65065-470 - São Luís - MA

MARIA DE FATIMA SANTOS - profafatima@hotmail.com UNIVERSIDADE FEDERAL DO MARANHÃO

Rua das Siriemas 01

65075-390 - São Luis - MA

Paulo Rogerio de Almeida Ribeiro - paulo.ribeiro@ecp.ufma.br UFMA

Rua projetada 8

65064-459 - São Luís - MA

Maira Silva Ferreira - mairaqm@hotmail.com

Universidade Federal do Maranhão

Avenida 0101

65063-050 - São Luís - MA

Resumo: $O$ presente trabalho tem como objetivo minimizar a evasão e consequentemente ampliar a permanência das mulheres nos cursos de graduação das áreas de ciências, tecnologia, engenharia e matemática (science, technology, engineering and mathematics - STEM) de uma Instituição de Ensino Superior do Estado do Maranhão por meio de ações de interação universidade-empresa. A aproximação das alunas ao mercado de trabalho do setor industrial possibilita uma 
percepção da articulação entre a prática de ensino e a realidade do mundo do trabalho, proporcionando o desenvolvimento de uma visão crítica e reflexiva sobre o universo corporativo. Atividades como minicursos de capacitação, mesas redondas, visitas técnicas e rodas de conversa, são parte das estratégias para minimizar a evasão das alunas nessas áreas. As atividades foram desenvolvidas localmente e são parte integrante das ações do projeto de extensão Sarminina Cientistas, sob a ótica da permanência de mulheres nos cursos em STEM Os resultados alcançados demonstraram um avanço significativo na motivação, formação e capacitação das alunas, ratificando a necessidade de se implantar alternativas de aprendizagem que estimulem a fixação das estudantes, minimizando a evasão no ensino superior.

Palavras-chave: Evasão. Mulheres. STEM. Interação universidade-empresa. Sarminina Cientistas. 


\section{AÇÕES DE INTERAÇÃO UNIVERSIDADE-EMPRESA COMO FORMA DE MINIMIZAR A EVASÃO DAS MULHERES NOS CURSOS DE STEM}

\section{INTRODUÇÃO}

A escassez de profissionais em ciências, tecnologia, engenharia e matemática (science, technology, engineering and mathematics - STEM) atinge diversos países. No Brasil, uma das causas para esse fenômeno é a alta evasão de estudantes nos cursos de ensino superior dessas áreas (SACARRO, 2019).

A evasão de alunos nos cursos de graduação no Brasil é um problema conhecido e de incidência histórica (HOED, 2016). Em cursos de engenharia, por exemplo, a média nacional de evasão, entre 2001 e 2011 , foi de $50 \%$, segundo pesquisas de Oliveira et al., (2013).

Quando se discute a evasão considerando-se a diversidade de gênero, o problema é ainda maior. Dados da Pesquisa Nacional por Amostra de Domicílios (PNAD) divulgados em 2016, mostram que a maioria das mulheres que ingressam no ensino superior em áreas tecnológicas, abandona o curso no primeiro ano, a exemplo dos cursos relacionados à Tecnologia da Informação, onde $79 \%$ das estudantes desistem no primeiro ano (PROGRAMARIA, 2016).

Segundo Cech e Blair-Loy (2019) o desequilíbrio de gênero nos campos de ciência, tecnologia, engenharia e matemática permaneceu inalterado por décadas, aumentando quanto mais longe se avança ao topo de carreira na área de STEM.

O estudo "Decifrar o código: educação de meninas e mulheres em ciências, tecnologia, engenharia e matemática-STEM", publicado em 2018 pela UNESCO, (Organização das Nações Unidas para a Educação, a Ciência e a Cultura), relata que as mulheres abandonam as disciplinas de STEM em quantidades desproporcionais durante seus estudos na educação superior, em sua transição para o mundo do trabalho e até mesmo durante sua carreira profissional.

Isso nos leva a refletir nas seguintes questões: o que leva uma mulher a desistir da carreira em STEM? Como manter motivadas as estudantes de graduação para que não haja evasão? Logo, baseada nessa reflexão, entendemos que para aumentar a participação feminina na área de STEM é necessário, inicialmente, identificar as razões que originam esta baixa representatividade, e posteriormente desenvolver ações para atraí-las e fixá-las nos cursos de graduação dessas áreas.

Pesquisas realizadas por Cunha (2001) e Bôas (2003) demonstram que a evasão tende a crescer se as Instituições de Ensino Superior não envolverem seus estudantes em atividades de pesquisa e extensão, já que estas permitem a união entre teoria e prática no processo de ensino e aprendizagem.

Cavalcante e Embiruçu (2013) concordam com os pensamentos de Cunha e Bôas ao afirmarem que a Universidade tem um elevado grau de responsabilidade na criação das condições necessárias para promover o atendimento das expectativas dos estudantes e a permanência dos alunos no curso até sua graduação.

Com efeito, as condições que determinam a permanência dos estudantes nos cursos do ensino superior estão mais relacionadas ao ambiente e às condições de aprendizado oferecidas pela instituição do que propriamente aos atributos dos estudantes (CAVALCANTE e EMBIRUÇU, 2013; apud TINTO, 2003).

Diante deste contexto, e considerando que a exposição à oportunidades de aprendizagem similares à do mundo real, tais como atividades extracurriculares, podem 
ajudar a inspirar e a manter o interesse das meninas, o projeto de extensão universitária "Sarminina Cientistas: Estimulando Meninas do Maranhão para as Carreiras de Exatas e Tecnologia", aprovado pela chamada $n^{\circ} 31 / 2018-C N P q$, implantou, em colaboração a empresas locais, atividades de capacitação às estudantes, visando minimizar a evasão e aumentar o interesse destas pela ciência e a sua disposição para permanecer e seguir carreiras em STEM.

\section{Interação universidade-empresa: minimizando a evasão de estudantes}

A aproximação entre as instituições universitárias e os setores industriais e de serviços tem se intensificado nos últimos anos, considerando a sua importância na formação dos futuros profissionais. Esta aproximação, tem ocorrido de diversas formas, dentre as quais : oferta de cursos, treinamento para capacitação, educação continuada, serviços de consultoria e extensão universitária (LUCIANO e OLIVEIRA, 2003).

Neste artigo, em particular, destaca-se 0 relacionamento baseado no ensino/aprendizagem/ambiente corporativo: a capacitação das alunas de graduação por profissionais da área, oferecendo uma formação vinculada aos avanços tecnológicos para construção conjunta do conhecimento.

As atividades para engajamento e fixação de mulheres em STEM, por intermédio da interação com o mundo real, palco de futuros ambientes de trabalho, surgiram como proposta de levar mais informações, conteúdo ou práticas utilizadas nas empresas, não constantes nos currículos pedagógicos dos cursos, tendo como diferencial uma construção conjunta nos ambientes de treinamento das próprias empresas.

\section{METODOLOGIA}

Para o desenvolvimento deste trabalho foram adotadas quatro etapas: (a) levantamento das necessidades/atividades para complementação da formação das alunas; (b) planejamento organizacional das ações juntos às empresas; (c) divulgação e (d) realização e avaliação das ações.

Inicialmente, foi proferida uma palestra de apresentação do projeto Sarminina Cientistas às alunas dos diversos cursos de graduação do Centro de Ciências Exatas e Tecnologia (CCET) de uma Instituição de Ensino Superior do Estado do Maranhão: Química, Química Industrial, Física, Matemática, Ciência da Computação, Bacharelado Interdisciplinar em Ciência e Tecnologia, Design e Engenharias (Química, Civil, Elétrica, Computação, Mecânica, Aeroespacial e Ambiental e Sanitária), e em seguida identificouse, junto às alunas, quais seriam as atividades que elas almejavam realizar como complemento à sua formação.

A segunda etapa do trabalho constou na formalização da parceria entre o grupo responsável pela condução do projeto, com o setor de recursos humanos $(\mathrm{RH})$ das empresas locais e/ou setor técnico, para verificar a disponibilidade e interesse da empesa em contribuir com o projeto. As empresas parceiras foram a AMBEV, Eletronorte, Eletrovisão e Vale e todas aceitaram ser parceiras do projeto.

Diversas atividades foram realizadas e posteriormente realizadas, de modo a contemplar as mais diferentes metodologias de sensibilização e formação, tais como: (i) a realização de mesa redonda para discutir as transições que acontecem na vida profissional, por exemplo: o primeiro emprego, o ambiente de trabalho e a posição de liderança no mercado de trabalho, (ii) roda de conversa para discussão de oportunidades de crescimento de carreira, preconceito, equidade de gênero e casos de sucesso, (iii) capacitações em campos de crescente desenvolvimento, a exemplo do curso de Controlador Lógico Programável e (iv) visitas técnicas em prol da qualificação, além da percepção da relação 
entre a teoria e a prática, proporcionando o desenvolvimento de uma visão crítica e reflexiva sobre a realidade.

\subsection{Mesa Redonda}

A primeira atividade do projeto contemplou o protagonismo feminino, com a realização de dinâmicas sobre profissões na mesa redonda "Mulheres nas Ciências Exatas e Engenharias: conquistas e desafios".

A mesa redonda contou com a participação de profissionais femininas que atuam nos setores acadêmicos, empresariais, no Conselho Regional de Engenharias e Agronomia do Estado do Maranhão (CREA-MA), além da participação de ex-alunas dos cursos do CCET integradas ao mercado de trabalho.

A atividade, que teve como viés discutir as transições que acontecem na vida profissional, tais como o primeiro emprego e o ambiente de trabalho, foi mediada por uma aluna do curso de engenharia elétrica e integrante do projeto.

Por meio de uma conversa descontraída, as convidadas contaram sobre suas trajetórias de vida e elencaram as maiores dificuldades encontradas ao longo de suas jornadas profissionais, desde 0 ingresso na universidade até o presente momento. Em seguida, ocorreu o debate junto ao público.

Na Figura 1 são apresentadas fotografias das participantes da mesa redonda.

Figura 1:- Registro de: (a) Profissionais participantes da mesa redonda; (b) Momento de culminância da equipe do projeto e do público participante do evento

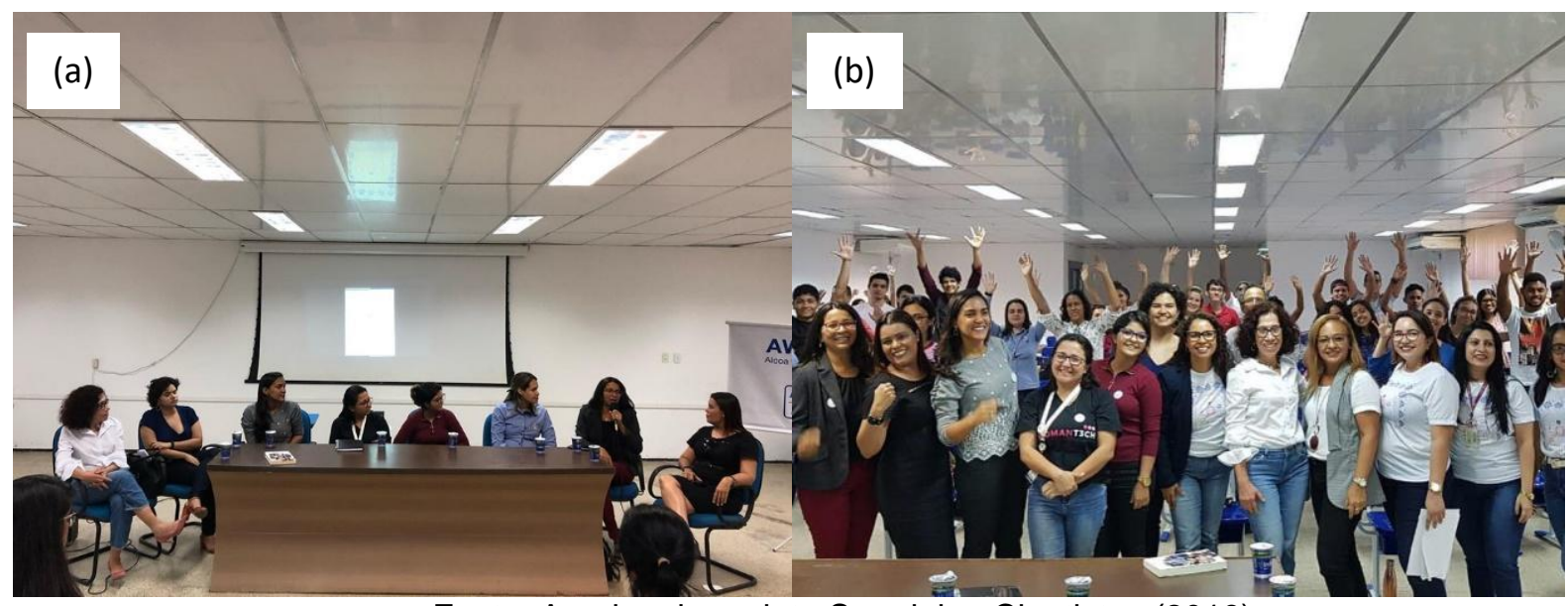

Fonte: Arquivo do projeto Sarminina Cientistas (2019)

\subsection{Cursos de capacitação}

Os cursos de capacitação foram definidos com o objetivo de complementar algum conteúdo trabalhado nas disciplinas ou fornecer ferramentas adicionais que contribuam no desempenho das alunas nos cursos de graduação.

\section{Curso de Controlador Lógico Programável}

A indústria moderna está cada vez mais automatizada e, para se inserir neste mercado, é essencial que o profissional tenha noções básicas de como funciona a automação industrial. A base da automação industrial está no estudo de CLP Controladores Lógicos Programáveis.

Aprender a programar um CLP é um diferencial na área da automação industrial. Estando presente em praticamente todos os processos de automação de sistemas produtivos, o CLP funciona como um "cérebro", responsável por gerenciar todas as funções 
desempenhadas pelo sistema, desde leitura de status até o acionamento de maquinários, por exemplo.

Ao longo do curso de capacitação as alunas conferiram alguns conceitos teóricos para o bom entendimento e o funcionamento de um CLP na prática: introdução ao controle lógico programável; características, aplicações, princípios e operações de um CLP e a apresentação do processo a ser automatizado (estudo de caso). Ressalta-se que os cursos de graduação a exemplo da engenharia elétrica e engenharia da computação, possuem, em seus projetos pedagógicos, disciplinas que abordam o tema de automação industrial e CLP. Contudo, o ambiente da empresa é um ambiente industrial real. Logo, essa capacitação demonstrando problemas do dia a dia da empresa completa o aprendizado já realizado na universidade.

A Figura 2 registra o momento das alunas no curso de CLP em ambiente corporativo.

Figura 2: Alunas durante o curso de capacitação em CLP

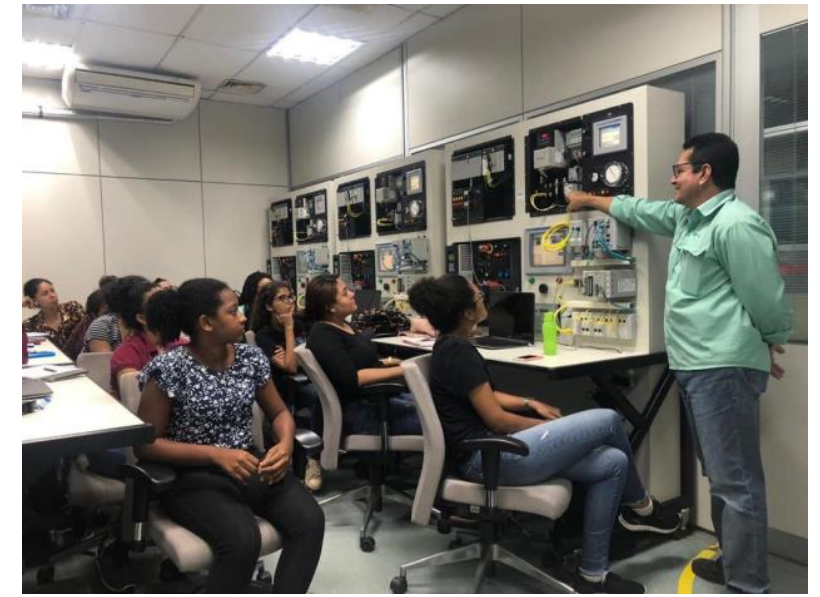

Fonte: Arquivo do projeto Sarminina Cientistas (2019)

\section{Processos de Fabricação de Cerveja}

Hoje existem muitas mulheres atuando na criação e produção nas cervejarias, assim como dentro de todo o mercado cervejeiro, como sommelières, professoras, cervejeiras, pesquisadoras, entre tantas outras atividades ligadas à prática e cultura cervejeira. Nesse sentido, com intuito de fornecer uma visão geral da indústria cervejeira e diversificar o contato das alunas com o setor produtivo, foi idealizada uma capacitação na área de produção de cerveja.

A realização do minicurso foi estruturada em dois momentos. No primeiro, foram abordados os processos básicos da produção da cerveja: preparo do mosto, fermentação, filtração e envase. Foram analisadas o efeito de algumas variáveis de processo, como a temperatura, o tempo e as diferentes quantidades e tipos de matérias-primas empregadas no processo, que podem gerar uma gama de cervejas com características singulares. No segundo momento, as alunas puderam se familiarizar, na prática, com diferentes tipos de cerveja.

A Figura 3 apresenta duas fotografias das alunas que participaram do minicurso.

Figura 3: Processos de fabricação de cerveja: (a) alunas assistindo o minicurso; (b) ao final do minicurso 

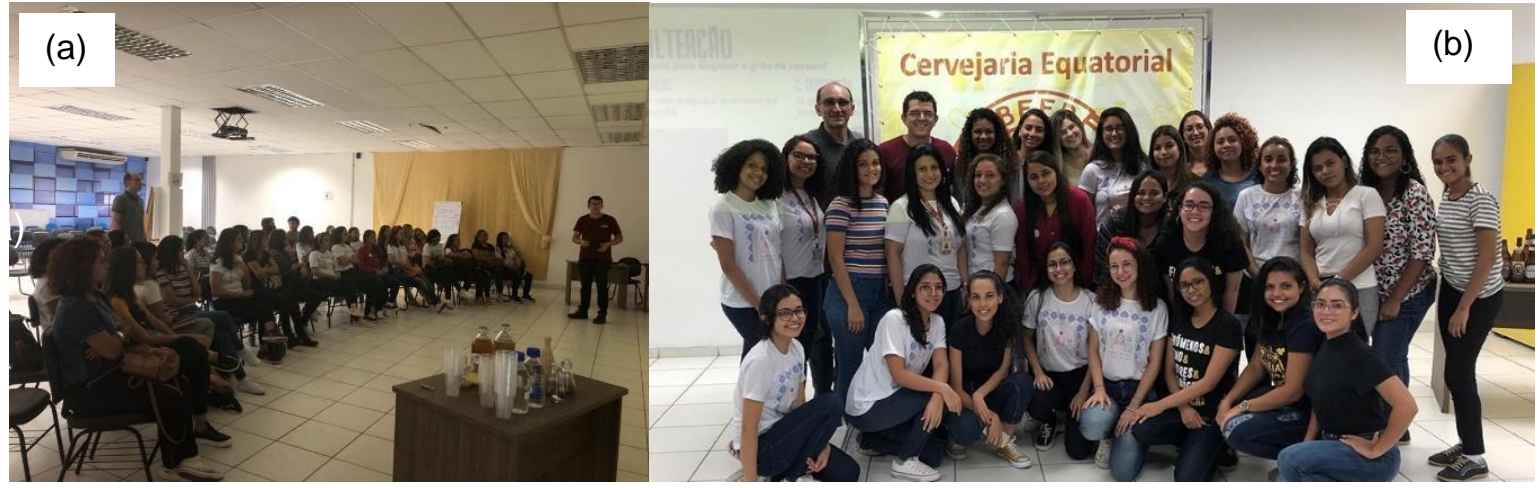

Fonte: Arquivo do projeto Sarminina Cientistas (2019)

\subsection{Visitas técnicas}

As visitas técnicas foram realizadas nas seguintes empresas da grande São Luís: Fábrica de refrigerantes e cervejas - AMBEV, Vale, Eletronorte e Elétrica visão.

Primeiramente, em cada empresa visitada, um funcionário realizava uma breve apresentação das normas de segurança e de como funcionava a empresa. Em seguida, as alunas eram direcionadas aos setores específicos das visitas. Todas as visitas eram conduzidas por supervisores setoriais, de modo que as alunas recebiam orientação técnica acerca do processo observado.

Durante as visitas as alunas tiveram a oportunidade de vivenciar o cotidiano e o fluxo das empresas, proporcionando o conhecimento de como se dá a vivência de rotinas as quais irão compor as atividades correspondentes a sua profissão. Observaram também, alguns potenciais ramos de atuação relacionados à sua formação, o que poderá contribuir para que futuramente possam ter parâmetros que as ajudem a decidir de forma consciente a área que mais se adequa ao seu perfil profissional.

A Figura 4 representa a fotografia das alunas durante as visitas técnicas.

Figura 4: Visita Técnica: (a) Ambev (b) Elétrica Visão (c) Eletronorte (d) Vale 


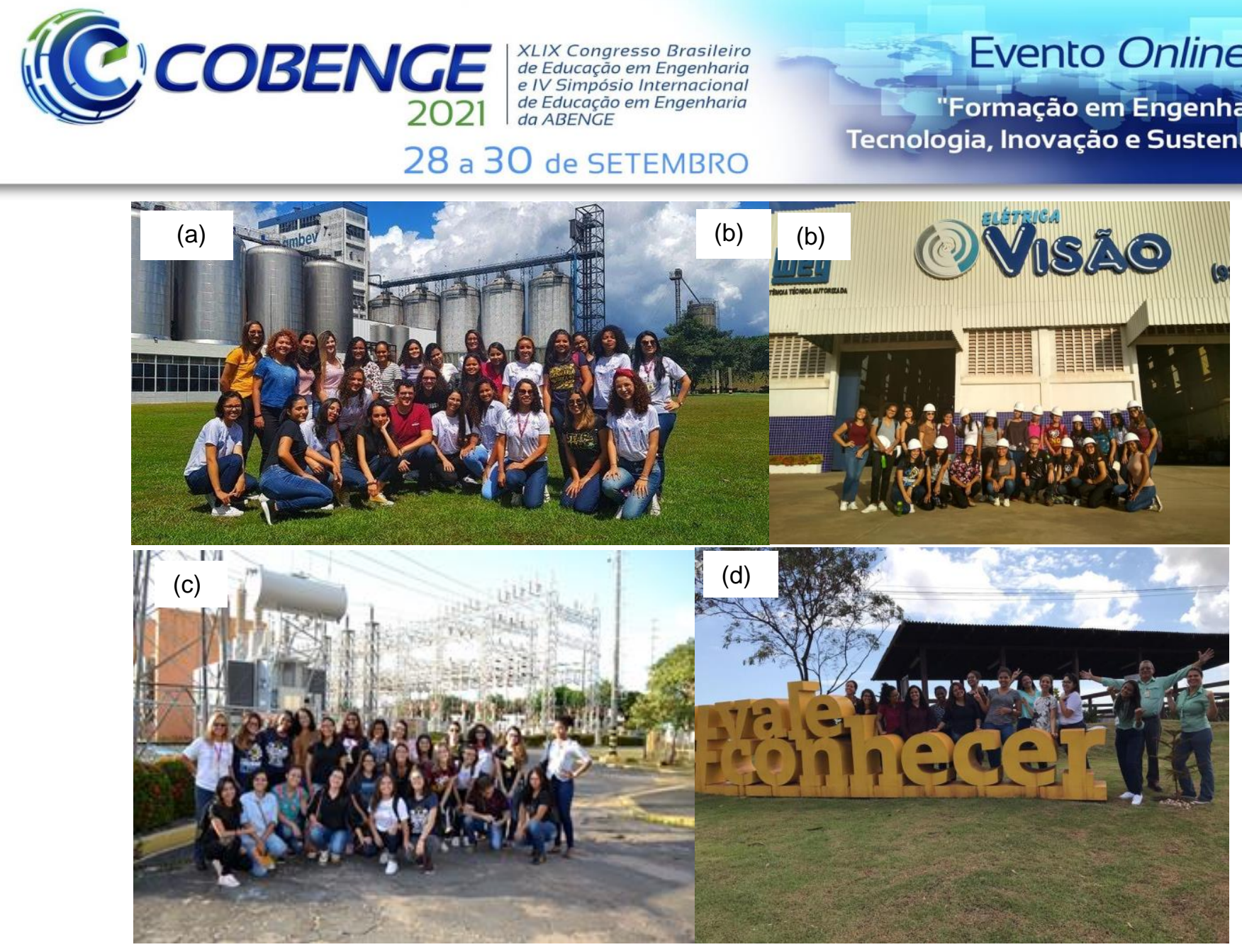

Fonte: Arquivo do projeto Sarminina Cientistas (2019)

\subsection{Roda de conversa}

Como parte das atividades comemorativas alusivas ao Dia da Mulher -8 de março, a empresa Vale promoveu uma roda de conversa para debater as oportunidades de crescimento de carreira, preconceito, equidade de gênero e casos de sucesso na empresa.

A finalidade foi enfatizar temas ligados ao empoderamento feminino com debates protagonizados pelas principais líderes femininas em suas áreas de atuação na empresa.

Durante a roda de conversa ocorreram debates em torno de como é ser mulher e homem na sociedade contemporânea. Houve uma reflexão de como retornar ao trabalho após a maternidade, além da discussão sobre assuntos como liderança e dificuldades profissionais.

A Figura 5 mostra fotografias do momento da roda de conversa.

Figura 5: Roda de conversa: (a) alunas; (b) líderes femininas da empresa Vale

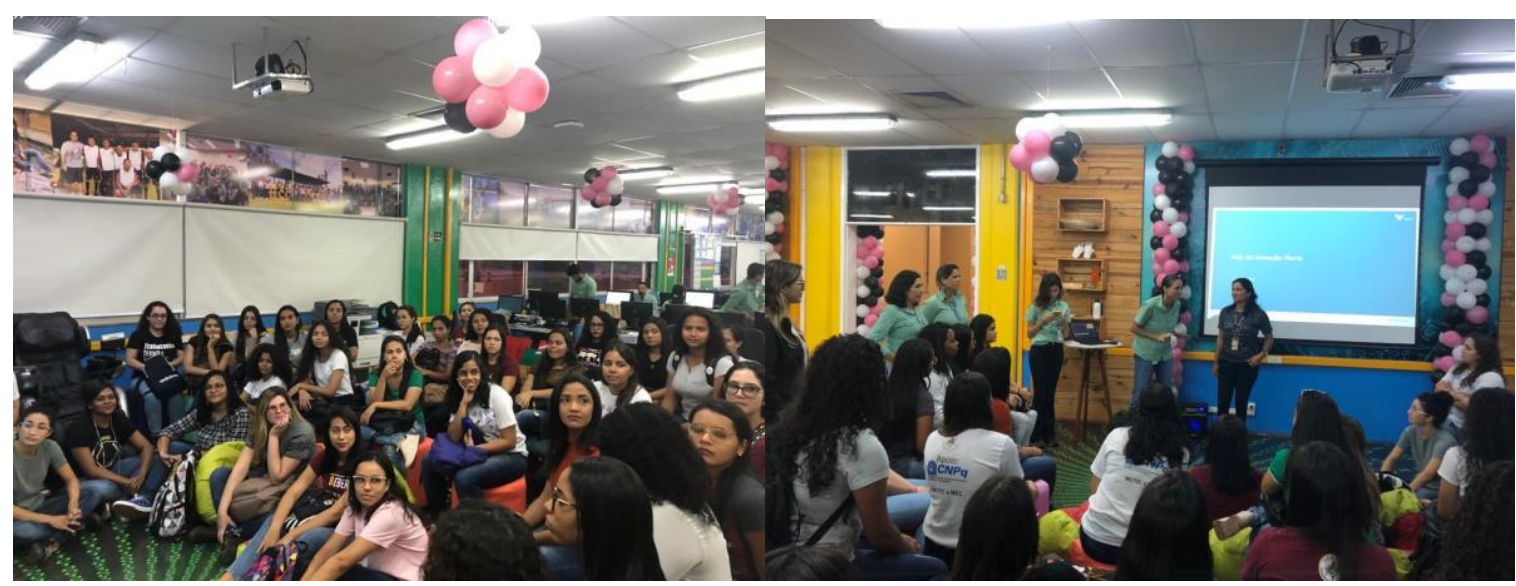


Uma das principais motivações do presente estudo é avaliar e concluir sobre a percepção das alunas quanto as atividades realizadas. Logo, as alunas foram convidadas a preencher um questionário de pesquisa de opinião, de forma anônima e voluntária, após a finalização das ações. O questionário foi desenvolvido na plataforma Google Forms, contemplando questões objetivas e subjetiva destinadas à avaliação das ações, e sua relação com os objetivos esperados: satisfação, aprendizagem, motivação e engajamento.

\section{RESULTADOS E DISCUSSÕES}

Os resultados obtidos com a pesquisa de opinião são apresentados nessa seção. Participaram da pesquisa 21 alunas matriculadas nos cursos de Bacharelado Interdisciplinar em Ciência e Tecnologia, Ciência da Computação, Engenharia Ambiental e Sanitária, Engenharia Civil, Engenharia Elétrica, Engenharia Química e Química Industrial.

Os resultados da avaliação são apresentados neste trabalho em forma de gráficos para uma melhor interpretação e visualização dos resultados das respostas coletadas no questionário.

As Figuras 6 e 7 apresentam, respectivamente, o grau de satisfação e percepção das alunas sobre as ações do projeto.

Figura 6: Grau de satisfação quanto as ações realizadas

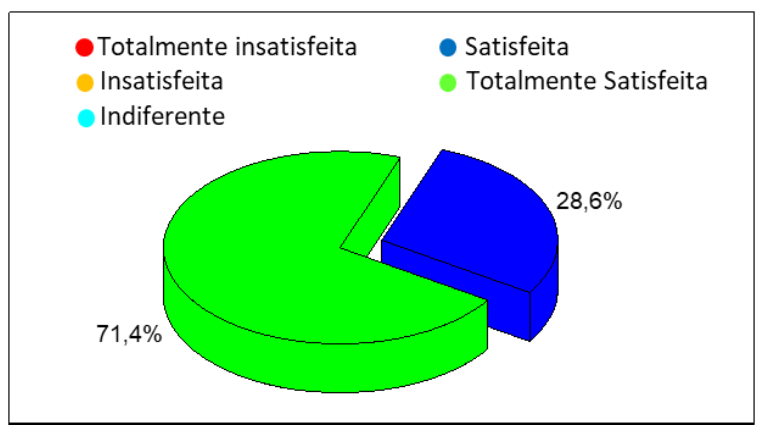

Fonte: Autor (2019)

Ao analisar os dados apresentados na Figura 6, verifica-se que o grau de satisfação foi bastante positivo. A maioria das alunas, $71,4 \%$, ficaram totalmente satisfeitas com a realização das ações do projeto. Este resultado é um importante indicador de quão promissor foram as ações aqui apresentadas

Quando questionadas se as ações do projeto ajudaram a perceber a área de STEM de uma forma diferente, as alunas foram unânimes em afirmar que sim, sendo que $71,4 \%$ das entrevistadas concordaram plenamente e $28,6 \%$ concordaram com o questionamento (FIGURA 7). Ademais, as alunas foram unanimes em afirmar que se sentiram mais motivadas à sua profissão após participarem das atividades do projeto. 


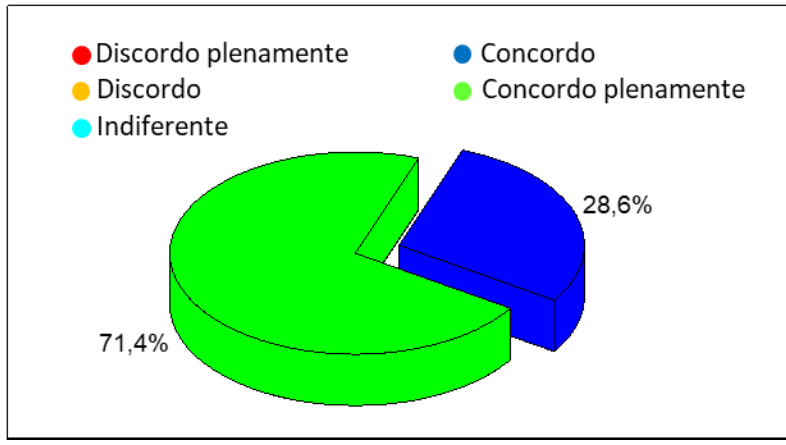

Fonte: Autor (2019)

Um outro aspecto investigado foi a contribuição das ações na formação das alunas, cujos resultados estão apresentados na Figura 8.

Figura 8: (a) contribuição na formação do conhecimento; (b) desempenho nos estudos
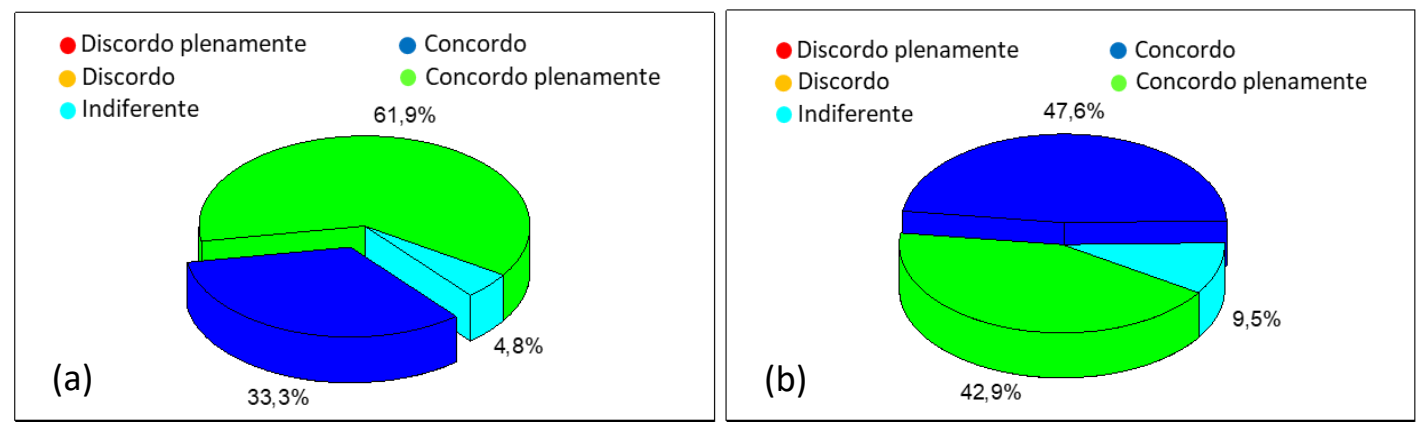

Fonte: Autor (2019)

A Figura 8a destaca que a maioria das aulas afirmaram que a ações do projeto contribuíram para sua formação na área de STEM e que por sua fez fizeram melhorar nos estudos (FIGURA 8b).

A Figura 9 apresenta os resultados obtidos da avaliação dos minicursos de capacitação.

Figura 9: Avaliação dos minicursos de capacitação

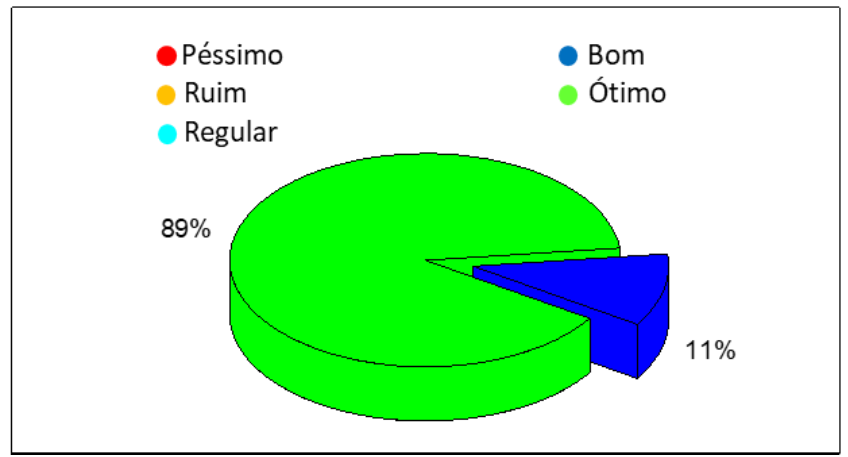

Fonte: Autor (2019) 
A partir da análise da Figura 9, verifica-se que as alunas avaliaram positivamente os minicursos de capacitação: $89 \%$ classificaram os minicursos como ótimos, enquanto $11 \%$ com bom. Este resultado é muito motivador para equipe do projeto, nos incentivando cada vez mais a oferecer, sempre que possível, cursos diversificados para complementação da formação das alunas.

Quando questionadas se os cursos foram relevantes para sua formação e se estes são aplicáveis na sua rotina de estudo ou trabalho, as participantes foram unânimes em afirmar que sim, ratificando a importância desta ação.

A Figura 10 mostra o resultado da avaliação referente às visitas técnicas.

Figura 10: (a) grau de contribuição das visitas técnicas no conhecimento; (b) associação com conteúdos teóricos vistos em sala de aula; (c) motivação após visita técnica

(a)

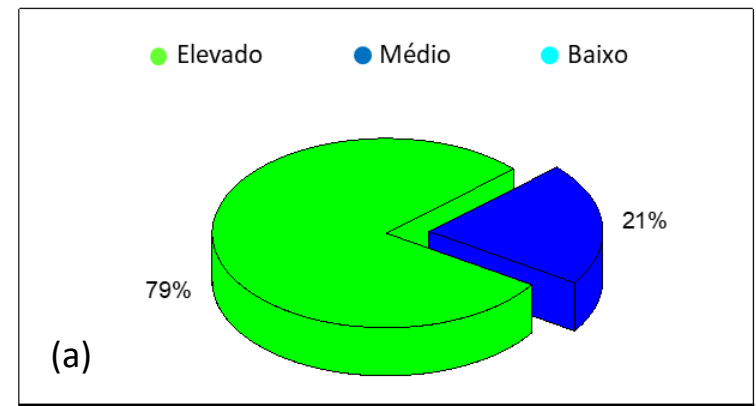

(b)

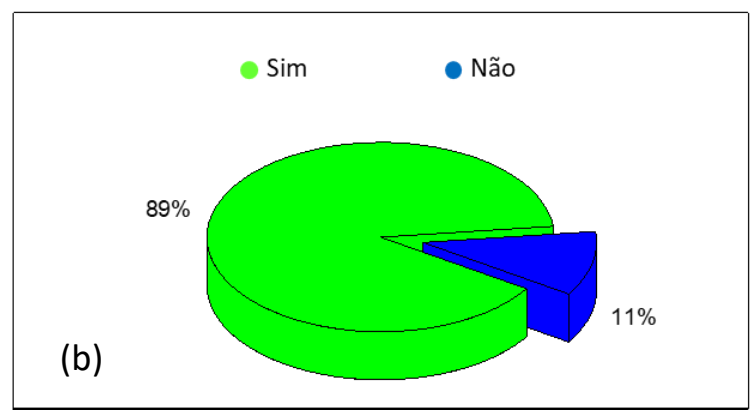

(c)

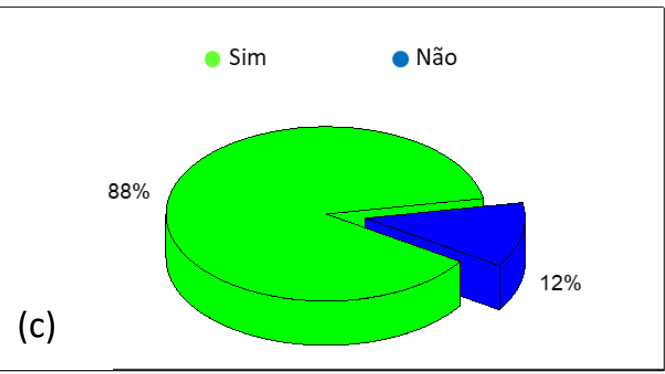

Fonte: Autor (2019)

Os resultados apresentados na Figura 10 são muito importantes para avaliar a contribuição das visitas técnicas na formação das alunas. Verificou-se a partir destes resultados que a maioria das alunas, $79 \%$, afirmaram que as visitas técnicas contribuíram em um grau elevado para a formação do seu conhecimento (FIGURA 10a) e que $89 \%$ das participantes relacionaram o conteúdo teórico, ministrado em sala de aula, com a experiência de campo (FIGURA 10b). Quando questionadas se ficaram motivadas com a profissão após as visitas, $88 \%$ das participantes responderam que sim. Considerando que as visitas técnicas eram abertas ao público feminino dos diversos cursos em STEM do CCET, é possível que está avaliação insatisfatória (12\%) esteja relacionada a participação de meninas oriundas de cursos que não tinham uma relação direta com o tema abordado na visita.

Quando questionadas se a experiência na visita técnica apresentou algum aspecto positivo, a compilação dos dados do questionário mostrou os seguintes resultados:

a) Ela me mostrou que é esse caminho mesmo que quero seguir, devido ao que foi apresentado pelo orientador e pela gratidão das pessoas ao nos mostrarem o seu trabalho que é feito com muito orgulho. (Aluna 01, Engenharia Elétrica, 2019)

b) Como mulher, me senti mais capaz e com mais força para mudar a estatística machista vigente. (Aluna 02, Engenharia Elétrica, 2019) 
c) Pude aprender que mesmo para uma coisa tão simples, por trás é necessário um trabalho enorme para entregar algo de qualidade (Aluna 03, Engenharia Química, 2019).

d) Uma visão bem transparente de como funciona a produção de uma indústria. (Aluna 04, Química Industrial, 2019)

e) Houve transparência por parte do palestrante sobre os processos que foram utilizados para a obtenção do produto e foi possível atrelar algo teórico que aprendemos em sala sendo colocado na prática. (Aluna 05, Engenharia Química, 2019).

f) Mudou algumas das minhas perspectivas sobre o curso, e me fez ampliar meus conhecimentos sobre a área. (Aluna 06, Engenharia Elétrica, 2019).

g) $\quad \mathrm{Me}$ fez ver o real significado do curso que estou fazendo (Aluna 07, Engenharia Química, 2019).

h) Sim!! Porque pude escutar diretamente dos engenheiros eletricistas o campo de atuação. Isso me fez me encontrar nas ideias e perspectivas da empresa assim como no campo de trabalho. Muito importante também foram os estímulos que os palestrantes nos deram para seguir em frente no nosso curso. (Aluna 08, Engenharia Elétrica, 2019).

O resultado deste trabalho possibilitou considerar positiva as ações realizadas pelo projeto Sarminina Cientistas. Segundo os dados aqui apresentados as ações contribuíram positivamente à formação das alunas, proporcionando momentos e experiências dificilmente oferecidas dentro de uma sala de aula, contribuindo na motivação para que estas permaneçam na área de STEM.

Por fim, entendemos que o objetivo do projeto foi atingido, exemplificada pela seguinte resposta de uma das estudantes: "Essa visita foi um diferencial na minha vida acadêmica, porque eu estava meio que desanimada com todo o cansaço de fim de período na UFMA. Acontece que toda a turbulência das provas, laboratórios, projetos, etc, acaba nos cobrando além do normal e, muitas vezes, esquecemos do nosso amor pelo curso ou área e apenas nos ligamos a essa correria. Nesse dia, pude ver como é gratificante o poder de uma MULHER na área e isso me inspirou continuar lutando e não mais me entregar apenas ao cansaço diário. Conclui que, o tamanho esforço valerá a pena e devo apenas ter tais coisas em mente. As duas mulheres que falaram com a gente foram minha grande inspiração para tal percebimento" (Aula 09, Engenharia Elétrica, 2019).

\section{CONSIDERAÇÕESFINAIS}

As atividades apresentadas neste trabalho são parte integrante da metodologia do projeto Sarminina Cientistas, sob a ótica da permanência de mulheres nos cursos em STEM.

Os resultados alcançados neste trabalho demonstraram um avanço significativo na motivação, formação e capacitação das alunas, ratificando a necessidade de se implantar alternativas de aprendizagem que estimulem a fixação das estudantes, minimizando a evasão no ensino superior. Corroboramos com Mello et al (2015, apud Barlem et al., 2012) quando afirmam que para conter a evasão há de ter maior aproximação dos estudantes com a realidade profissional, momentos de discussão e reflexão, favorecendo tanto a autonomia como a valorização profissional e pessoal. Demonstraram também que a troca de informação e o desenvolvimento das habilidades profissionais essenciais à participação no mercado de trabalho é de suma importância.

Com os primeiros resultados positivos pretende-se: (i) prosseguir com acompanhamento constante das alunas participantes do projeto e (ii) dar continuidade às atividades de incentivo a mulheres na área de STEM, seja por meio das redes sociais ou 
webinars, devido a pandemia ocasionada pela COVID-19, a fim de que outras alunas se sintam motivadas em suas carreiras profissionais.

\section{Agradecimentos}

A equipe envolvida neste trabalho agradece às empresas pela disponibilidade, assim como ao CNPq pelo financiamento do projeto (processo $n^{\circ} 442951 / 2018-3$ ).

\section{REFERÊNCIAS}

BÔAS, G. K. V. Currículo, iniciação científica e evasão de estudantes de ciências sociais. Revista Tempo Social, São Paulo, v. 15, n. 1. p. 45-62, 2003.

CAVALCANTE, Fernando P. L; EMBIRUÇU, Marcelo S. Aprendizado com Base Em Problemas: Como Entusiasmar Os Alunos E Reduzir A Evasão Nos Cursos De Graduação Em Engenharia. In: XLI Congresso Brasileiro de Educação em Engenharia, 2013, Rio Grande do Sul. Anais. Gramado. Disponível em: https://turing.pro.br/anais/COBENGE2013/pdf/116536 1.pdf. Acesso em 20 abr. 2021.

CECH E.A., BLAIR-LOY, M. The changing career trajectories of new parents in STEM. Proc Natl Acad Sci, U S A. v. 119, n.10, p. 4182 - 4187, 2019.

CUNHA, A. M.; TUNES, E.; SILVA, R. R. Evasão do curso de química da Universidade de Brasília: a Interpretação do Aluno Evadido. Química Nova, São Paulo, v. 24, n. 1, p. 262280, 2001.

HOED, Raphael Magalhães. Análise da evasão em cursos superiores: o caso da evasão em cursos superiores da área de computação. 2016. Dissertação (Mestrado Profissional em Computação Aplicada) - Curso de Computação. Universidade de Brasília, Brasília, 2016.2 Disponível em: https://repositorio.unb.br/bitstream/10482/22575/1/2016 RaphaelMagalh\%c3\%a3esHoed. pdf. Acesso em 21 abr. 2021.

LUCIANO, Benedito Antônio; OLIVEIRA, Talvanes Meneses. Interação universidadeempresas mediante estágios curriculares. In: 3rd International Conference on Engineering and Computer Education. 2003, São Paulo, Anais. São Paulo. Disponível em https://copec.eu/congresses/icece2003/proc/pdf/T620.pdf. Acesso em 24 abr.2021.

MELLO, Simone Portella Teixeira de, MELO, Pedro Antônio, FILHO, Raul Teixeira de Mello Estudando a evasão no ensino tecnológico em uma instituição de ensino superior no sul do Brasil. EccoS Revista Científica [en linea]. 2015, (37), 181-196. Disponível em: https://www.redalyc.org/articulo.oa?id=71543111011. Acesso em 26 de abr. 2021.

OLIVEIRA, Vanderlí Fava et al. Um estudo sobre a expansão na formação em engenharia no Brasil. Revista de ensino de engenharia. v. 32, p. 29-44, 2013.

PROGRAMARIA (2016). Ser mulher em tech. Site Programaria. Disponível em https://www.programaria.org/sermulheremtech/ . Acesso em: 28 abr. 2021.

SACARRO, A; FRANÇA, M. T. A.; JACINTO, P. A. Fatores Associados à Evasão no Ensino Superior Brasileiro: um estudo de análise de sobrevivência para os cursos das áreas de 
Ciência, Matemática e Computação e de Engenharia, Produção e Construção em instituições públicas e privadas. Estud. Econ., São Paulo, vol.49 n.2, p.337-373, 2019.

UNESCO. Decifrar o código: educação de meninas e mulheres em ciências, tecnologia, engenharia e matemática (STEM). - Brasília: 2018. 84 p., il. ISBN: 978-85-7652-231-7. Disponível

https://ead2.iff.edu.br/pluginfile.php/138994/mod resource/content/1/Decifrar\%200\%20CO DIGO.pdf.Acesso em 28 abr. 2021.

\title{
UNIVERSITY-INDUSTRY INTERACTIONS AS WAY TO REDUCE WOMEN DROPOUT OF STEM COURSES.
}

\begin{abstract}
The present work aims to reduce evasion and consequently increase the permanence of women in courses in the fields of Science, Technology, Engineering and Mathematics (STEM) at the Federal University of Maranhão (UFMA) through universityindustry interaction. The approach of the students to the industrial job market allows a perception of the articulation between teaching practice and the reality of the world of work, providing the development of a critical and reflective view of the corporate universe. Activities such as training courses, round tables, technical visits and conversation circles are part of the strategies to minimize student dropout in these areas. The activities presented here were developed locally and are an integral part of the actions of the extension project "Sarminina" Scientists.
\end{abstract}

Key Words: Dropout. Women. STEM. University-Industry Interaction. "Sarminina" Scientists. 